\title{
COASTAL DISASTER RISK ASSESSMENT AND DESIGNATION OF PROTECTION ZONING IN TAIWAN USING GIS
}

\author{
LIEN KWEI CHIEN, WEI PO HUANG, CHIH HSIANG HSU, CHING CHIEH HSIEH \& CHEN YANG FANG \\ Department of Harbor and River Engineering, National Taiwan Ocean University, Taiwan
}

\begin{abstract}
Due to the loss of coastal land by intensified global climate change, the threat to the lives and property of people is becoming more serious, and the disaster risk assessment and management of coastal areas is becoming an important issue. Based on the Coastal Management Act, in this study, the four hazard factors such as sea-level rise, subsidence, storm surge flooding, and coastal erosion are discussed. Further, the hazard index and the designating principles for coastal protection zone are established and designated as first-grade and second-grade coastal protection zones. In addition, the vulnerability index includes physical factors', natural environmental factors', social-economic factors', and resilience factors' relationships with urban development. Use of the Pareto ranking method can remove the weight factor to establish a comprehensive assessment of the index rating respectively. Then, combined with coastal hazards and the vulnerability index for disaster risk analysis of coastal areas, a risk map can be generated via geographic information systems. The study results can provide a reference for disaster adaptation and coastal management and utilization.

Keywords: Coastal Zone Management Act, protection zone, vulnerability index, hazard factor, risk assessment, GIS.
\end{abstract}

\section{INTRODUCTION}

Around a hundred years ago, Taiwan's average temperature increased $1.3^{\circ} \mathrm{C}$. This is not only 2 times more than the increase of the average global temperature, but also higher than nearby countries, such as Japan and China. Due to an increase in Taiwan's rainfall, disasters are happening more and more frequently. Most of Taiwan's land areas face a serious subsidence problem, as sea-level rise will bring serious disasters to coastal lowland areas, such as the Lan-Yang Plain. Therefore, impacts caused by climate change and global warming are now significant issues for the safety of Taiwan's coastal community. According to the increasing impact on coastal areas, many countries attach importance to decreasing coastal disasters and adopting mitigation strategies. To make the planning and management of Taiwan's coastal areas more appropriate, the Coastal Management Act was implemented in February 2015. Article 14 in the Coastal Management Act, which mentions coastal protection zones, reveals the aim of avoiding coastal disaster and national land loss.

The different hazard factors such as sea-level rise, land subsidence, storm surge flooding, and coastal erosion were discussed to set up the hazard index for coastal areas. The physical factors, natural environmental conditions, social-economics, and resilience are adopted to evaluate the vulnerability index of coastal areas. In this study, using Pareto's ranking method, which ignores each factor's weight, we combine hazard and vulnerability factors with a risk matrix to analyse coastal area risks. This can provide a reference for the designated protection guidelines of coastal areas. Based on the coastal risk assessment, the first grade and second grade of coastal protection zones can be designated. Finally, with the use of Geographic Information Systems (GIS), a risk map for each coastal area is generated. To make the research results more suitable and follow the principle of Taiwan's Coastal Management Act, our research focuses on a case of Taiwan's coastal land area. This study provides a reference 
for the designation of coastal protection zones, decision-making during coastal disasters, and management strategies on climate change.

\section{HAZARDS AND VULNERABILITY OF COASTAL AREAS}

\subsection{Study area}

To maintain natural systems and ensure zero loss of natural coastlines, determine the countermeasures of climate change, prevent coastal hazards and environmental damage, protect and restore coastal resources, promote the integration of coastal management and the sustainable development of coastal areas, the Coastal Management Act in Taiwan was published. According to the article 5 of the Coastal Management Act, central authorities need to consider ecological environment characteristics and integrity, the influence between foreshore and land, and the necessity and feasibility of managing coastal areas. The Ministry of the Interior of Taiwan announced the designated coastal area on 4 August 2015. This range of coastal area in Taiwan includes 95 towns, as shown in Fig. 1.

\subsection{Hazards of coastal areas}

According to articles 9 and 16 of the Coastal Management Act, an integrated coastal zones management plan must be established. Coastal protection zones can help develop the coastal protection program. As for coastal protection zones, Taiwan's agency performed the Act of Coast Management to explain which coastal area is vulnerable to coastal erosion, subsidence,

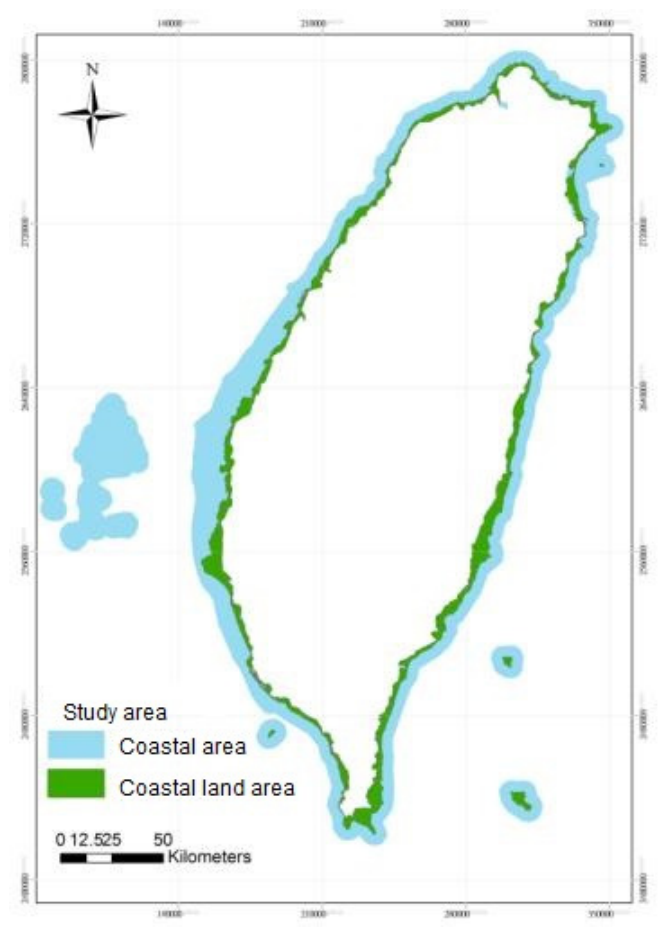

Figure 1: Range of coastal area, designated by the Coastal Management Act in Taiwan [1]. 
flooding, storm surge flooding and other disaster conditions. It can designate the protection area as first grade and second grade; the decision to formulate a first-grade coastal protection program is coordinated by the central competent authority, and the local county authority formulate the second-grade coastal protection program. Based on the Coastal Management Act, in this study, the four hazard factors - sea-level rise, subsidence, storm surge flooding, and coastal erosion - are discussed [2], [3].

\subsubsection{Sea-level rise}

On the basis of the IPCC Fifth Assessment Report, a set of four representative concentration pathways (RCPs) which are determined by globalization, market economics, different regions and the conscience of environmental protection, have been developed. In this study, sea-level rise caused by climate change and four different RCPs were adopted, as shown in Table 1.

\subsubsection{Land subsidence}

The subsidence data are based on an Industrial Technology Research Institute (ITRI) report from 2009, and land-subsidence prevention and reclamation crop, from the Ministry of Economic Affairs; although, the speed of land subsidence has slightly decreased recently. However, the actual speed of land subsidence comprises about 1 to $3 \mathrm{~cm}$ per year. The reports indicate that if the subsidence still increases steadily, the average subsidence might range from 1 to $1.5 \mathrm{~m}$ during the end of the 21 st century. In that case, this study takes the simulated condition of land subsidence during the end of the 21 st century as a research condition indicator.

\subsubsection{Storm surge flooding}

Lai et al. [5] indicated that there are two primary factors that induce a storm surge. One is low-pressure of the typhoon centre, inducing water-level rise, and the other one is caused by strong winds. The typhoon best track data by the Regional Specialized Meteorological Center (RMSC) from 1951 to 2013 was collected. By using MIKE 21, DHI - the Institute for Water and Environment's mathematical model - the storm surge distribution is calculated in different return periods by applying extreme value statistics analyses. The results are shown in Table 2. Concerning the condition during the late-21st century, this study adopts storm surge deviation around the north-western coastal area of Taiwan (ranges from 1.2 to $1.5 \mathrm{~m}$, and return period is 100 years), which might be the most seriously affected area, to be researched as a condition indicator.

\subsubsection{Coastal erosion}

Based on the qualitative classification in Taiwan shoreline changes trend [6] and the principle of protection zone disaster potentials at Coastal area overall land use protection strategy investigation [7], the coastal erosion analysis was performed. Qualitative classification of hazard and coastal erosion condition is shown in Table 3.

Table 1: Four representative concentration pathways (RCPs) (IPCC [4]).

\begin{tabular}{|l|l|}
\hline$R C P$ condition & Sea-level rise height \\
\hline A1 RCP 8.5 & $0.52 \mathrm{~m}-0.98 \mathrm{~m}$ \\
\hline A2 RCP 6 & $0.33 \mathrm{~m}-0.63 \mathrm{~m}$ \\
\hline B1 RCP 4.5 & $0.32 \mathrm{~m}-0.63 \mathrm{~m}$ \\
\hline B2 RCP 2.6 & $0.26 \mathrm{~m}-0.55 \mathrm{~m}$ \\
\hline
\end{tabular}


Table 2: Storm surge distribution in different return periods [5].

\begin{tabular}{|l|l|l|l|}
\hline \multirow{2}{*}{ Coastal zone } & \multicolumn{3}{l}{ Return period } \\
\cline { 2 - 4 } & 10 years & 50 years & 100 years \\
\hline North coastal area & $0.7-0.9 \mathrm{~m}$ & $0.8-1.2 \mathrm{~m}$ & $0.9-1.4 \mathrm{~m}$ \\
\hline North-western coastal area & $0.9-1.1 \mathrm{~m}$ & $1.1-1.3 \mathrm{~m}$ & $1.2-1.5 \mathrm{~m}$ \\
\hline Middle coastal area & $0.4-0.8 \mathrm{~m}$ & $0.5-1 \mathrm{~m}$ & $0.6-1.3 \mathrm{~m}$ \\
\hline South-western coastal area & $0.3-0.4 \mathrm{~m}$ & $0.4-0.6 \mathrm{~m}$ & $0.5-0.7 \mathrm{~m}$ \\
\hline East coastal area & $0.4-0.5 \mathrm{~m}$ & $0.5-0.8 \mathrm{~m}$ & $0.6-0.9 \mathrm{~m}$ \\
\hline
\end{tabular}

Table 3: Classification of coastal erosion levels.

\begin{tabular}{|l|l|}
\hline Level & Erosion subscription \\
\hline 1 & Continuous erosion and silting \\
\hline 2 & No significant change \\
\hline 3 & Long-term change, no significant change in short term \\
\hline 4 & Potential erosion area that still has a buffering zone, such as a sandy beach \\
\hline 5 & High potential erosion area that has no buffering zone, such as a sandy beach \\
\hline
\end{tabular}

This study simulated hazard conditions such as sea-level rise, land subsidence, storm surge flooding and coastal erosion for the discussed coastal areas. We then evaluated how those hazard factors affect Taiwan's coast. The influence of a hazard area and its ratio is evaluated under the different conditions. In this study, a percentage of accumulated influence on the inundated area of up to $50 \%$ is a critical value. This represents half of the coastal area that has suffered flood hazards. The simulated hazard condition indicators are shown in Table 4.

\subsection{Vulnerability index of coastal area}

In this study, the related vulnerability index and data for the Taiwan coastal area were collected. The vulnerability index of the Taiwan coastal area was discussed using physical, environmental, social-economical and resilience indicators. In addition, by using the Pareto ranking (PR) method, which can avoid different proportional impacts on a given output, a general assessment and indicator ranking was established to provide a more suitable vulnerability map for Taiwan's coast [8]-[10].

Table 4: Simulated hazard conditions.

\begin{tabular}{|l|l|}
\hline Level & Simulated hazard condition \\
\hline 1 & No hazard \\
\hline 2 & $\begin{array}{l}\text { Inundated area (including sea-level rise, storm surge and land subsidence: total height is } \\
\text { below } 4 \mathrm{~m})>50 \%\end{array}$ \\
\hline 3 & $\begin{array}{l}\text { Inundated area (including sea-level rise, storm surge and land subsidence: total height is } \\
\text { below } 3 \mathrm{~m} \text { ) }>50 \%\end{array}$ \\
\hline 4 & Inundated area (including sea-level rise and storm surge: total height is below $2 \mathrm{~m}$ ) $>50 \%$ \\
\hline 5 & Inundated area (sea-level rise: total height is below $1 \mathrm{~m}$ ) $>50 \%$ \\
\hline
\end{tabular}




\subsubsection{Physical vulnerability indicator}

The physical vulnerability indicator considers coastal area exposure during disaster, the probability of regional hazards, and impact degrees. It includes population density and coastal protection such as the ratio of sea-wall length.

Population density: population density is defined as a measurement of population per unit area. Population data are accessed from population statistics provided by the Department of Statistics, Ministry of the Interior. Population density can be calculated using the population in each town of the coastal area divided by the area of each town.

Ratio of the sea-wall length: the longer the length of the sea wall, the better engineering defence capability (based on the databank of the Water Resources Agency, MOEA). The ratio of sea-wall length can calculate the total length of sea walls in each town of a coastal area divided by the total length of the boundary in each town of a coastal area. As the region's ratio of sea-wall length gets higher, regional vulnerability gets lower.

\subsubsection{Environmental vulnerability indicator}

In this study, the environmental vulnerability indicator is referred to using the USGS's coastal vulnerability factors. The coastal geomorphology and environmental sensitivity area was adopted to evaluate the environmental vulnerability indicator.

Coastal geomorphology: primarily, coastal geomorphology in Taiwan is sandy coast, and shoreline landform is usually coral coast. Most of the time, the structural strength of a sandy coast is weaker and a coral coast is more stiff. Therefore, this study gives each landform a different ranking grade (data resource is based on the Water Resources Agency, MOEA).

Environment sensitive area: the environment sensitive area is easily affected by human improper development. According to the range of environment sensitive areas by the Ministry of the Interior, this study designated the high-risk coastal area into first-grade or second-grade ranking, which is based on the severity of the condition. As a result, an environment sensitive area in a coastal zone is ranked with a higher vulnerability grade.

\subsubsection{Social economics of vulnerability indicator}

The social economics of a vulnerability indicator considers exposure, meaning damaged condition, while human, facility and structure in disaster. The higher the damage those areas experience, the bigger the economic loss to the area. In this study, the social economics of the vulnerability indicator includes a development condition of the coastal area and regional average individual income.

Development condition of coastal area: existing land use is an important economic orientation in coastal areas. This study adopts the current land use, such as urban and rural development, and industrial and agricultural land use. If a coastal area is belonging to a constructed area, then the grade of vulnerability becomes the highest. If a coastal area is within a high agricultural land use area, then the grade of vulnerability becomes second highest. If there are neither urban and rural development land use nor agricultural land use, then the grade of vulnerability becomes the lowest.

Regional average individual income: if the average individual of regional resident's income becomes higher, then the region will suffer greater impacts of a hazard. Therefore, the higher the average individual income of regional residents is, the higher the vulnerability grade.

Each socio-economics vulnerability indicator gives a grade. The higher the level of vulnerability indicator ranks, the higher the vulnerability grade becomes. We then take the sum of each region's total grade and separate those regions into five levels. 


\subsubsection{Resilience of vulnerability indicator}

The resilience of the vulnerability indicator shows the recovery capacity of human society, economics and the environment after suffering a disaster. The resilience of vulnerability factors include local government budget and local government fire-fighter ratio.

Local government budget: the higher the local government budget, the more budget can be used for recovery after disaster. Therefore, the higher the local government budget is, the higher the vulnerability grade.

Local government fire-fighter ratio: if the local government fire-fighter ratio is higher, then more manpower can be used to recover the area after disaster. Therefore, the higher the local government fire-fighter ratio is, the higher the vulnerability grade.

\section{DISASTER RISK ANALYSIS OF COASTAL AREA}

\subsection{Method of disaster risk analysis}

Chien et al. [7] defined the range for Coastal Protection Areas (CPA), based on the suggestion of assessment disaster risk by the International Strategy for Disaster Reduction (ISDR). Risk can be defined as the combination of the hazard and the vulnerability. In 2004, the ISDR published a definition of risk and the basic formula (see eqn (1)); a variety of natural disaster risks research mainly follows the guidelines of the natural disaster risks assessment method.

$$
R=H(\text { hazard }) \times V(\text { vulnerability }) .
$$

Based on the current status and protection targets at coastal areas, this study developed nine principles of CPA to ensure the sustainable development of coastal areas [7]. The flow chart of the designated process of CPA is shown in Fig. 2.

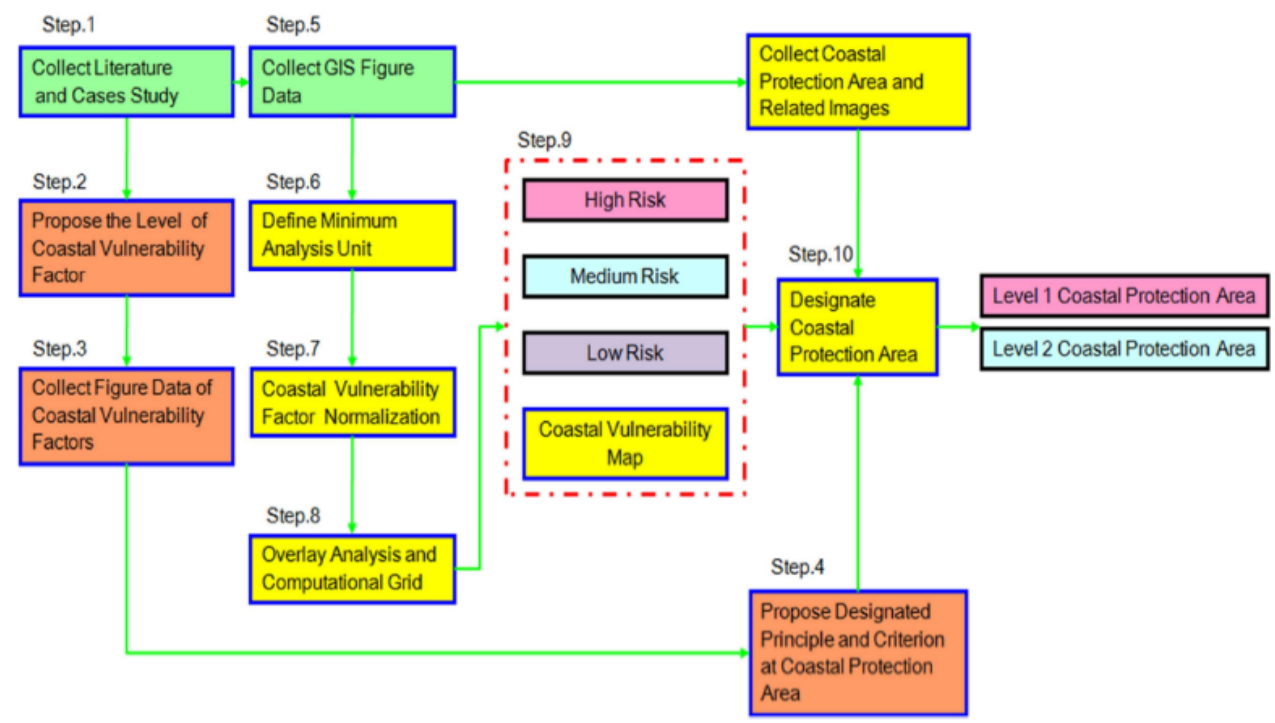

Figure 2: Flow chart of the designated process of coastal protection areas [7]. 
In this study, the coastal disaster potential analysis was performed under climate change to simulate sea-level rise, land subsidence and storm surge by discussing these simulations affected by sea-level rise, and by generally analysing how coastal erosion affects coastal residents and national land loss. In addition, by using PR analysis, each coastal vulnerability index grade was obtained. Finally, the coastal risk map is established by integrating each coastal vulnerability index grade and hazard ranking. The concept of the coastal risk assessment and risk matrix are shown in Figs 3 and 4.

\subsection{Pareto ranking (PR) analysis}

Pareto ranking analysis typically indicates that a disproportionate improvement can be achieved by ranking various causes of a problem and by concentrating on those solutions or items with the largest impact. The basic premise is that not all inputs have the same or even proportional impact on a given output. This study uses PR analysis because it is difficult to integrate factors in the study. Before using PR analysis, those factors have to be standardized using eqns (1) and (2). After getting a standardized grade, we sum the total grade of each region vulnerability indicator (such as the grade of each vulnerability indicator, level 1 to 5) and integrate those hazard indicators into six levels. Hazard indicators are defined as sea-level rise, land subsidence and storm surge flooding. Finally, by using PR analysis, the risk assessment of the coastal area is performed, and each region is assigned a hazard risk level. The highest risk region gets level 9, the lowest gets level 1, based on the principle of PR analysis and evaluation of each regional vulnerability.

$$
z \text {-score }=(X i-M) / S \text {, }
$$

where $X i$ : different indicators' data; $M$ : average grade; and $S$ : standard deviation.

$$
\mathrm{S}=\sqrt{\frac{\sum\left(x_{i}-M\right)^{2}}{N-1}}
$$

where $N$ : number of data.

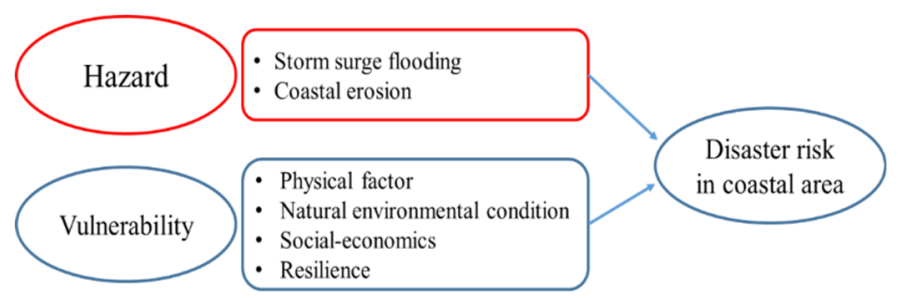

\begin{tabular}{|c|c|c|c|c|c|c|c|}
\hline & \multicolumn{6}{|c|}{ Hazard level } \\
\hline & & 0 & 1 & 2 & 3 & 4 & 5 \\
\hline \multirow{5}{*}{ 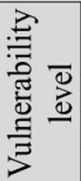 } & 1 & 0 & 1 & 2 & 3 & 4 & 5 \\
\hline & 2 & 0 & 2 & 4 & 6 & 8 & 10 \\
\hline & 3 & 0 & 3 & 6 & 9 & 12 & 15 \\
\hline & 4 & 0 & 4 & 8 & 12 & 16 & 20 \\
\hline & 5 & 0 & 5 & 10 & 15 & 20 & 25 \\
\hline
\end{tabular}

Figure 3: The concept of the coastal risk assessment.

Figure 4: The concept of the risk matrix. 


\subsection{Overlapping by GIS}

This study uses GIS to integrate statistical analysis and display. Each factor of vulnerability indicator ranges from level 1 to 5. The sum of each region's vulnerability indicator is taken, and integrated with those hazard indicators into six rankings using the PR method. Hazard indicators include sea-level rise, land subsidence and storm surge flooding. By combining with the simulated flooding and coastal erosion conditions, the coastal risk and each given regional hazard risk level, we can evaluate that the highest risk region is level 9 , and the lowest is level 1 by using of PR analysis.

\section{ANALYSIS RESULTS}

\subsection{Hazard analysis results}

By using PR analysis, the hazard risk of each regional coastal area can be designated. As per the results, most high-risk regions are located along the south-western coast of Taiwan and the Yilan coast. Those regions might be easily affected by storm surge flooding or coastal erosion. The integrated risk map of Taiwan coastal area is shown in Fig. 5.

\subsection{Vulnerability analysis results}

The vulnerability analysis includes physical factors, natural environmental conditions, social economics, and resilience. Using PR analysis, this study discerns that besides Hualian, Taitung and Miaoli, other regions have high vulnerability. The Taiwan vulnerability map is shown in Fig. 6.

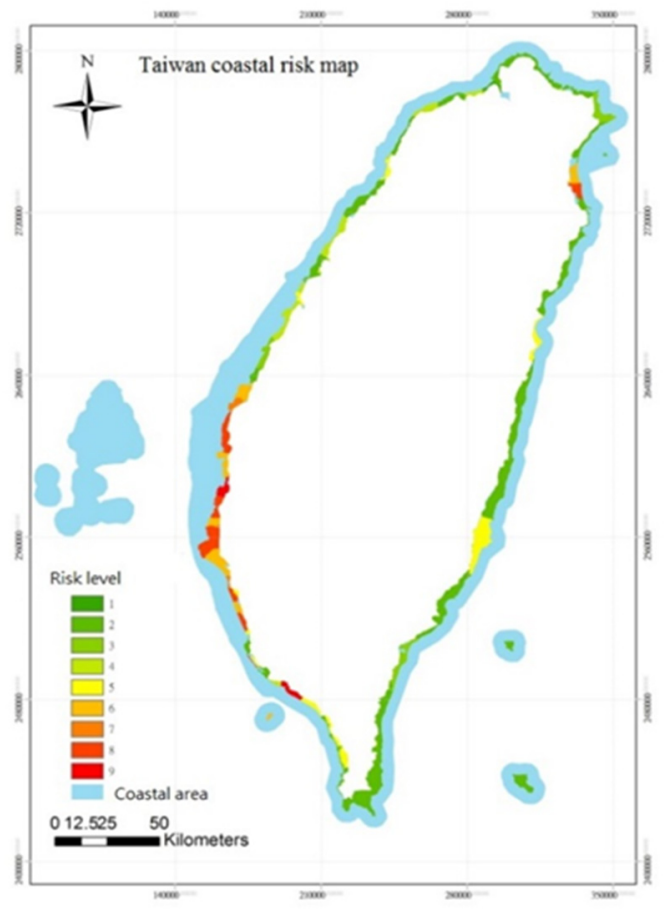

Figure 5: Risk map of Taiwan coastal area. 


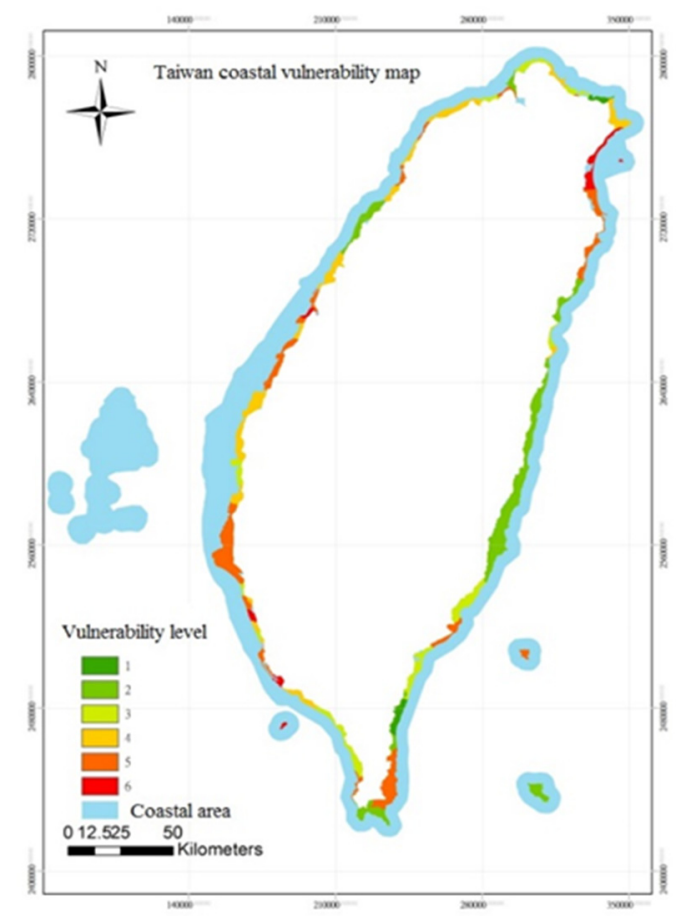

Figure 6: Vulnerability map of Taiwan coastal area.

\subsection{Risk analysis results}

In this study, the risk analysis was performed using GIS. Each coastal region's vulnerability indicator grade (the grade of each vulnerability indicator factor ranges from levels 1 to 5) is totalled and we integrate those hazard indicators into six levels. Hazard indicators include sea-level rise, land subsidence and storm surge flooding. Finally, by using PR analysis to evaluate general risk in coastal areas, the general hazard risk of a region can give a score. The highest risk region gets level 9, and the lowest gets level 1. Depending on each region's hazard risk level, the risk matrix can be used to separate those regions into five risk levels, such as high level, medium-high level, medium level, medium-low level and low level, respectively. From the analysis results, high vulnerability and hazard regions are located along the south-western Taiwan coast and the Yilan coast. Those medium-high risk and high risk regions are shown in Fig. 7.

In this study, the rank of a high-risk region, and medium-high risk region is designated as the first grade of a protection coastal area. And the rank of a medium risk region is designated as the second grade of a protection coastal area. Those first grade and second grade protection coastal zones include the low-lying south-western Taiwan coast and the Yilan alluvial plain. The first-grade of coastal protection area has 24 towns, and the second-grade of coastal protection area has 13 towns. Comparing those first grade and second grade protection zones defined in this study with the protection zones defined by the Water Resources Planning Institute, Water Resources Agency, protection zoning at coastal areas of low-lying 


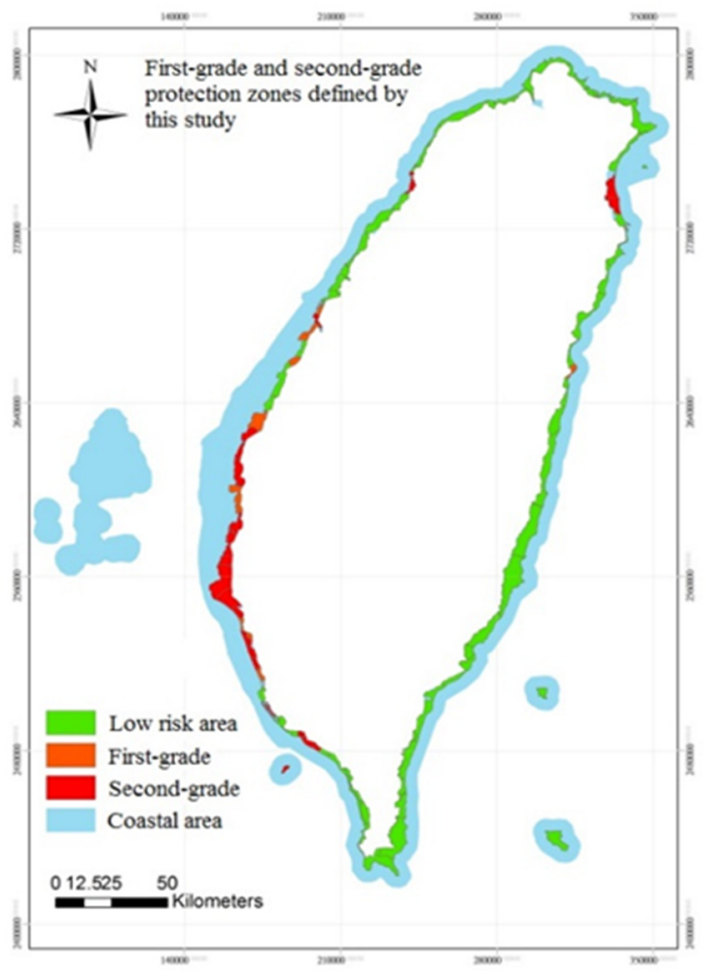

Figure 7: First-grade and second-grade protection coastal zones designated by this study.

south-western Taiwan and the Yilan alluvial plain are situated at almost the same location as that shown in Fig. 8, but the different risk-level zoning for other towns has different results. A possible reason for this is because of the different viewpoints while evaluating regional hazards and vulnerability. Zonal designations of this study are based on disaster risk, and those of the Water Resources Planning Institute are based on disaster potentials. Therefore, even if those areas are easily affected by disaster, if regional vulnerability is ranked lower, this study will consider those regions as having a lower disaster risk.

\section{CONCLUSIONS}

The risk assessment and management of coastal disaster is become an important issue under climate change. In this study, based on the Coastal Management Act, the four hazard factors such as sea-level rise, subsidence, storm surge flooding, and coastal erosion are discussed. According to the risk assessment results, the rank of a high-risk region, and a medium-highrisk region are designated as representing the first-grade of coastal protection areas. And the rank of a medium-risk region is designated as the second-grade of coastal protection areas. Those first-grade and second-grade protection zones include the coastal areas of low-lying south-western Taiwan and the Yilan alluvial plain. The central competent authority needs to perform an integrated coastal zone management plan for the conservation, protection, utilization, and management of coastal area land. In the future, we will make efforts to support the government agency and coastal community in maintaining Taiwan's natural environment and sustainable development. 


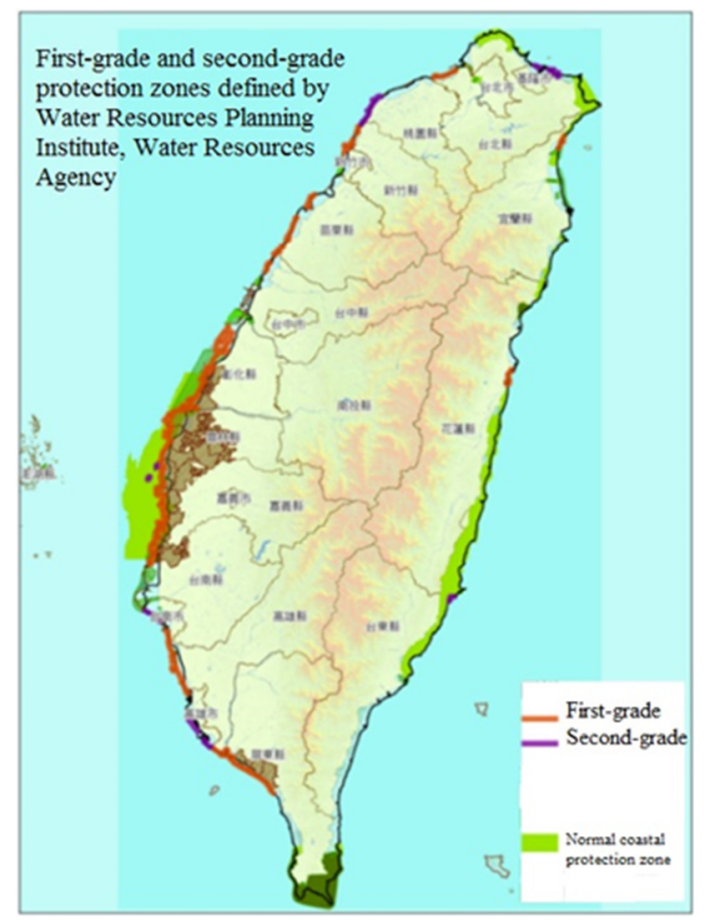

Figure 8: First-grade and second-grade protection zones designated by the Water Resources Planning Institute, Water Resources Agency.

\section{ACKNOWLEDGEMENTS}

Our thanks to the project "Operation Permission Assessment of Coastal Area Land Development and Environmental Risk Management (I) (MOST 105-2621-M-019-006)" and the Ministry of Science and Technology for their financial support.

\section{REFERENCES}

[1] Chien, L.K., Hsu, C.H., Huang, W.P. \& Wang, I.C., The study of designation of coastal protection zone and management in Taiwan. The 25th International Ocean and Polar Engineering Conference, Rhodes, Greece, 2016.

[2] Lin, H.Y., A study of risk assessment of land use for coastal area under climate change: The case of Yunlin coastal area, Department of Harbor and River Engineering, Master's thesis, National Taiwan Ocean University, 2015.

[3] Huang, W.P., Chien, L.K. \& Lee, L.H., Risk maps and coastal defence criteria in Taiwan. Journal of Marine Science and Technology, Journal of Marine Science and Technology, 24(6), pp. 1105-1114, 2016.

[4] IPCC, Fifth Assessment Report, Sea Level Change, 13, pp. 1137-1216, 2013.

[5] Lai, Y.T., Chu, J.C. \& Chen, Y.L., The distribution of storm surge deviation around Taiwan sea area in different return period. Proceedings of 36th Ocean Engineering Conference in Taiwan, pp. 119-124, 2014.

[6] Lin, T.Y. \& Weng, C.S., Analysis of shoreline changes on the Taiwan coast. Proceedings of the 35th Ocean Engineering Conference in Taiwan, pp. 377-382, 2013. 
[7] Chien, L.K., Tseng, W.C., Chiu, S.Y., Hsu, C.H. \& Hwang, W.P., Coastal vulnerability applied on prevention and management under climate change impact. Advanced Materials Research, 356-360, pp. 791-800, 2012.

[8] Chen, Y.T., Chien, L.K. \& Chang, C.H., A study on land use adaptation strategies in Taiwan's coastal area subjected to sea-level rise. Proceedings of the 35th Ocean Engineering Conference in Taiwan, pp. 559-564, 2013.

[9] Chien, L.K., Tseng, W.C., Chang, C.H. \& Hsu, C.H., A study of ocean zoning and sustainable management by GIS in Taiwan. Ocean \& Coastal Management, 69, pp. 35-49, 2012.

[10] Chien, L.K., Huang, W.P., Lee, B.C. \& Chang, C.H, The study on the protective standards and non-engineering strategy of the coastal defensive engineering. Water Resources Planning Institute, Water Resources Agency, Ministry of Economic Affairs, 2013. 